\title{
Entrevista com Murilo Fernandes Gabrielli, diplomata, Primeiro Secretário, atualmente lotado na Embaixada do Brasil em Ottawa
}

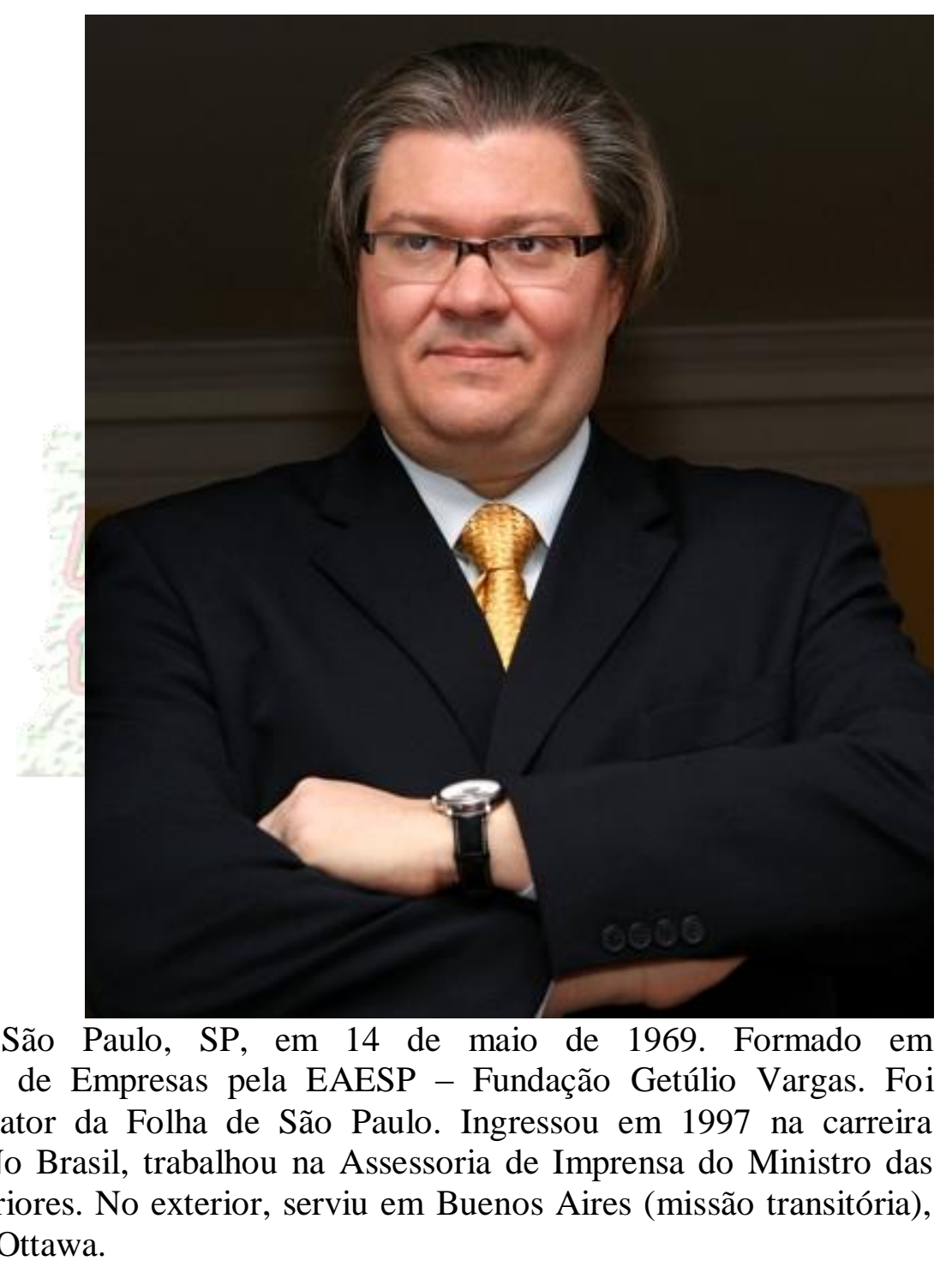

Nascido em São Paulo, SP, em 14 de maio de 1969. Formado em Administração de Empresas pela EAESP - Fundação Getúlio Vargas. Foi repórter e redator da Folha de São Paulo. Ingressou em 1997 na carreira diplomática. No Brasil, trabalhou na Assessoria de Imprensa do Ministro das Relações Exteriores. No exterior, serviu em Buenos Aires (missão transitória), Washington e Ottawa. 


\section{Revista Acolhendo: Murilo, fale um pouco das atividades realizadas pela Embaixada do Brasil em Ottawa.}

Bom, para usar um clichê, a diplomacia tem três funções básicas: informar, negociar, representar. Trata-se de uma definição antiga, mas que ainda muito bem resume o que fazemos no dia-a-dia de uma Embaixada.

Negociar não se resume a acordos internacionais - como o Memorando de Entendimento na área de saúde que os Ministros dos dois países firmaram recentemente em Genebra. Inclui ajudar a buscar soluções de comum acordo para qualquer irritante que apareça na relação bilateral. A Embaixada desempenhou, por exemplo, papel importante solução da disputa Embraer Bombardier.

Informar significa fornecer às autoridades brasileiras uma análise da situação política, econômica, financeira e cultural do Canadá. É claro que várias dessas informações podem, hoje, ser obtidas via internet. O papel da Embaixada é destacar as questões que mais interessam - ou podem vir a interessar - ao Brasil, filtrar esses dados pela ótica brasileira, complementá-las com informações de bastidores obtidas junto a autoridades e formadores de opinião canadenses.

$\mathrm{O}$ ato de representar o Brasil no Canadá inclui uma gama muito variada de atividades. Inclui participar de cerimônias oficiais do Governo canadense. Inclui manter contatos com representantes dos mais diversos setores da sociedade canadense. Inclui ajudar a promover as empresas e produtos brasileiros por aqui. Inclui dar palestras para empresários, acadêmicos, estudantes, funcionários de governo. Inclui atender às demandas da imprensa 
canadense sobre o Brasil. Incluir organizar eventos culturais e encontros acadêmicos sobre o Brasil.

\section{Revista Acolhendo: Como são as relações culturais entre Brasil e Canadá?}

São excelentes. O Ministério da Cultura brasileiro e o Ministério do Patrimônio do Canadá cooperam em vários níveis. No plano bilateral, estão negociando um Memorando de Entendimento que cria um quadro legal para iniciativas de cooperação cultural. Nos foros internacionais, em especial na Organização dos Estados Americanos e na UNESCO, as delegações de Brasil e Canadá têm, no que se refere a cultura e preservação do patrimônio, posições muito parecidas. Não raro votamos de modo igual e colaboramos na proposta de textos finais para convenções.

O Brasil e o Canadá mantêm também, há alguns anos, uma profícua parceria em produção audiovisual. Essa parceria tem funcionado muito bem, especialmente na área de animação - na qual o Canadá é um dos líderes mundiais e o Brasil tem-se desenvolvido muito. $\mathrm{O}$ mais recente filme do Fernando Meirelles, "Ensaio sobre a Cegueira", por exemplo, nasceu no seio desse acordo de coprodução.

Além disso, as Embaixadas e Consulados do Brasil no Canadá e do Canadá no Brasil têm aumentado o número de eventos culturais que organizam, de forma a promover o conhecimento recíproco. Estamos, por exemplo, no processo de selecionar os filmes para o primeiro Festival de Cinema Brasileiro de Ottawa, que terá lugar em outubro próximo.

Finalmente, há o crescente interesse do canadense pela cultura brasileira - em especial, me parece, no Quebec. É muito raro haver um festival de música por 
aqui sem a presença de um ou mais artistas brasileiros - confira, por exemplo, os nomes que constam da programação dos Festivais de Jazz de Montreal e Ottawa ou do Luminato em Toronto.

\section{Revista Acolhendo: A língua portuguesa tem sido ensinada no Canadá?}

O Ministério das Relações Exteriores ajuda a manter alguns Centros de Estudo Brasileiros pelo mundo. Eles estão presentes, por exemplo, em vários países latino-americanos, europeus e africanos. Infelizmente não temos nenhum aqui no Canadá. A Fundação Camões, de Portugal, mantém leitores em algumas universidades canadenses, caso de meu grande amigo Carlos Gomes da Silva, aqui na Universidade de Ottawa - a presença portuguesa no Canadá já data de algumas décadas e é bastante numerosa. O Carlos segue, em suas aulas de língua e cultura, um padrão muito comum entre os leitores da Fundação Camões: ensina português em suas várias vertentes, brasileira, portuguesa, angolana etc., sinalizando as diferenças existentes na sintaxe, prosódia e ortografia (embora estas tenham em muito diminuído com o acordo)

Não existe, que eu saiba, um levantamento oficial de todos os cursos de português existentes no Canadá.

Isso não quer dizer, porém, que não haja um sem número de escolas e professores particulares. Há vários excelentes cursos de português em nível universitário. Já citei o Carlos Gomes como exemplo. Poderia também lembrar da professora, mineira, Maria Apparecida de Almeida, do Centro de Pesquisas sobre o Brasil da UQAM.,

Revista Acolhendo: Com relação à língua e a cultura brasileira no mundo, o que você teria a dizer aos nossos leitores? 
Acho que o interesse pela cultura brasileira sempre houve, em especial por conta de nossa música. $\mathrm{O}$ cinema brasileirão também teve seus momentos de popularidade.

A novidade, a meu ver, dos últimos 15 anos, é o crescente interesse pela língua, que caminha pari passu com o crescente importância do Brasil no cenário internacional, quer econômica, quer política. É um fenômeno fácil de observar em nossos vizinhos sul-americanos - onde conhecer português pode representar hoje uma grande vantagem na hora de se conseguir um emprego melhor. Mas não apenas ali. Nos EUA, onde trabalhei entes de ser transferido para o Canadá, fiquei surpreso - agradavelmente surpreso - com o número de estudantes universitários que nos procuravam falando em bom português: tinham aprendido a língua por queriam se dedicar ao estudo do país. Dava lá palestras frequentes a estudantes de segundo grau.

\section{Como citar esta entrevista:}

ACOLHENDO, Revista. Entrevista com Murilo Fernandes Gabrielli, diplomata, Primeiro Secretário, atualmente lotado na Embaixada do Brasil em Ottawa. Revista ACOALFAplp: Acolhendo a Alfabetização nos Países de Língua portuguesa, São Paulo, ano 4, n. 7, 2009. Disponível em: <http://www.acoalfaplp.net>. Publicado em: setembro 2009.

Sede da Edição: Faculdade de Educação da Universidade de São Paulo - Av. da Universidade, 308 - Bloco A, sala 111 - São Paulo - SP Brasil - CEP 05508-040. Grupo de pesquisa: Acolhendo Alunos em situação de exclusão social e escolar: o papel da instituição escolar.

Parceria: Centro de Recursos em Educação Não-Formal de Jovens e Adultos - CRENF - FacEd - UEM - Prédio da Faculdade de Letras e Ciências Sociais - Segundo Piso - Gabinete 303 - Campus Universitário Maputo, Moçambique, África 